\title{
Intravenous analgesics for pain management in post- operative patients: a comparative study of their efficacy and adverse effects
}

\author{
Min $\mathrm{Li}^{1}$, Liang $\mathrm{Li}^{2}$, Yin-Tao $\mathrm{Xu}^{3}$ and Xia Wang ${ }^{4 *}$ \\ ${ }^{1}$ Department of Gynecology, ${ }^{2}$ Department of Anesthesiology, ${ }^{3}$ Department of Obstetrics, ${ }^{4}$ Department of Orthopedics, Qilu \\ Hospital of Shandong University, No. 107 Wenhua West Road, Jinan 250012, China
}

*For correspondence: Email: wangxia4560@163.com; Tel: +86 5318216 9114; Fax: 0086-531-82169114

Received: 7 February 2016

Revised accepted: 14 July 2016

\begin{abstract}
Purpose: To compare the effectiveness of post-operative pain management and associated adverse effects of ketamine and nefopam.

Methods: In total, 78 American Society of Anesthesiologists (ASA) grade 1 and 2 patients who had undergone abdominal surgery were given $3 \mathrm{mg}$ of intravenous (IV) morphine as post-operative analgesia. Patients who still had pain were randomly selected $(n=48)$ and separated into three groups, and infused with isotonic saline ( $n=15), 3 \mathrm{mg} / \mathrm{kg} / \mathrm{h}$ ketamine $(n=17)$, or $3 \mathrm{mg} / \mathrm{kg}$ nefopam $(n=16)$, respectively. Verbal rating scale (VRS), visual analogue scale (VAS), satisfactory scores, and total morphine consumption, as well as several adverse events were determined.

Results: VRS and VAS scores, and morphine consumption were significantly lower $(p<0.05)$ in the entire analgesic group than in the saline group. However, ketamine appeared to provide better ( $p<$ $0.05)$ analgesic activity. The satisfactory score was concomitantly elevated $(p<0.05)$ in the ketamine group. Moreover, the occurrence of adverse events was substantially lower $(p<0.05)$ in the ketamine group and was equivalent to nefopam group except sedation.

Conclusion: The combination of ketamine with morphine provides optimal pain relief in abdominal surgery patients and show fewer adverse effects than nefopam, thus achieving overall better satisfaction.
\end{abstract}

Keywords: Post-operative pain, Abdominal surgery, Adverse effects, Morphine, Ketamine, Nefopam

Tropical Journal of Pharmaceutical Research is indexed by Science Citation Index (SciSearch), Scopus, International Pharmaceutical Abstract, Chemical Abstracts, Embase, Index Copernicus, EBSCO, African Index Medicus, JournalSeek, Journal Citation Reports/Science Edition, Directory of Open Access Journals (DOAJ), African Journal Online, Bioline International, Open-J-Gate and Pharmacy Abstracts

\section{INTRODUCTION}

Post-operative pain continues to be a challenge and is often inadequately treated, leading to patient anxiety, stress, and dissatisfaction. Adequate analgesia within the beginning hours of the early post-operative period is important to curb the acute pain, which improves prognosis and prevents progression to chronic pain [1]. Post-operative pain is a major problem in surgical patients, especially after major abdominal surgery. Intravenous patient- controlled analgesia (IV-PCA) is a wellestablished technique for post-operative pain control. This technique prevents the patient from receiving excessive doses (overdosing), and it increases patient satisfaction and cooperation [2]. Morphine remains a gold standard analgesic used particularly for post-operative pain management. However, side effects tend to alter morphine titration, resulting in insufficient pain relief [3]. The combination of non-opioid analgesics with morphine provides a morphinesparing effect and may decrease dose-limiting 
toxicity. The use of a combination of analgesics from different pharmacological drug classes to manage post-operative pain should improve the safety and efficacy of pain therapy due to their different mechanisms of action and by limiting the severity of adverse events of the individual drugs, since opioids alone sometimes provide insufficient post-operative analgesia. Understandably, a demand exists for the clinical investigation of drugs with special reference to adverse events, for analgesic use as part of combination therapy during the post-operative period [4].

Ketamine, an N-methyl-D-aspartate (NMDA) non-competitive antagonist, has undergone a recent resurgence of interest amongst acute care providers as an adjunct in acute pain management [5]. Several studies demonstrate that it improves opioid analgesia and decreases the need for opioids immediately after surgery $[6,7]$. Blocking NMDA receptors via magnesiumdependent channels may improve the efficacy of opioids and reduce the risk of chronic pain syndromes [8]. Nefopam, a benzoxazine, is a cyclized analogue of diphenhydramine and a centrally acting, non-opioid analgesic. Intravenous (IV) infusion of nefopam quickly produces potent inhibition of the nociceptive flexion reflex in humans without binding to opiate receptors [9]. It provides morphine-sparing effects when given post-operatively during abdominal surgery [10]. In addition, nefopam indirectly modulates NMDA receptors and decreases c-Fos protein expression in the dorsal horn of the spinal cord in rats, and may reduce allodynia and hyperalgesia when combined with opioid [11]. Both ketamine and nefopam act as NMDA antagonists, modulating central sensitization and providing antihyperalgesic effects. Therefore, they could have a role in acute post-operative pain management by reducing the amount of opioids required and improving opioid effectiveness, which might also reduce their side effects. To the best of our knowledge, no studies have compared the efficacy and adverse effects of ketamine and nefopam as co-analgesics with morphine after major abdominal surgical procedures. Hence, the present study was aimed to evaluate whether these analgesic regimens improve recovery and improve patient satisfaction.

\section{METHODS}

A randomized, double-blind clinical trial was conducted in the post-anesthesia care unit (PACU) of Qilu Hospital of Shandong University in Jinan, China. The study was performed according to the guidelines of the Declaration of
Helsinki [4] and was registered with the Chinese Clinical Trials Registry (CCTR no. 003241). All procedures involving human subjects were approved by the ethics committee of Qilu Hospital of Shandong University (approval ref no. QHSU-372849). Written informed consent was obtained from all the patients prior to surgery.

\section{Study design}

One hundred and twenty-four patients of both genders who were scheduled to undergo abdominal surgery (hemicolectomy, exploratory laparotomy, extended radical cystectomy and nephrectomy, and abdominal aortic aneurysm surgery), who were between the ages of 18 to 70 years, and who were in good health or with mild systemic diseases according to the American Society of Anesthesiologists (ASA, grade 1 or 2) were recruited. Exclusion criteria were as follows: a psychiatric history, inability to understand the verbal rating scale (VRS) and the visual analogue scale (VAS), inability to use a patientcontrolled analgesia (PCA) device, previous treatment for chronic pain or treatment with opioids, known opioid allergies, chemical substance abuse, increased intracranial pressure, hepatic and renal pathology, and pregnancy. Patients undergoing emergency surgery were also excluded. During the preanesthetic visit, the VRS and VAS were explained to patients, and they were trained to use PCA devices. Seventy-eight patients were enrolled after the initial assessment.

\section{Induction of general anesthesia}

General anesthesia was induced with $3.0 \mathrm{mg} / \mathrm{kg}$ fentanyl, $5 \mathrm{mg} / \mathrm{kg}$ thiopental sodium, and 1.5 $\mathrm{mg} / \mathrm{kg}$ succinylcholine. Atracurium was maintained with isoflurane in $50 \%$ nitrous oxide and $0.3-1.3 \mu \mathrm{g} / \mathrm{kg} / \mathrm{min}$ sufentanil [8]. Neuromuscular relaxation was antagonized at skin closure, and patients were tracheally extubated before transfer to the recovery room. After surgery, patients were given supplemental oxygen at $5 \mathrm{~L} / \mathrm{min}$ via a facemask.

\section{Study protocol}

After arrival in the recovery room, residual neuromuscular blockade was reversed with neostigmine $(40 \mu \mathrm{g} / \mathrm{kg})$ and atropine $(15 \mu \mathrm{g} / \mathrm{kg})$ [8]. Post-operative pain was controlled by titration of IV morphine by nurses who were blinded to the grouping. The patients were administered morphine $(3 \mathrm{mg} / \mathrm{kg}$ with a lockout time of $20 \mathrm{~min}$ until $1 \mathrm{~h}$-programmed via IV-PCA infusion pump as post-operative analgesia in the recovery room. Patients who still experienced pain (VAS 
score > 40, with no acute respiratory or hemodynamic distress) were included in the analysis $(n=48)$ and separated into three groups using computer-generated random numbers. The three groups were infused intravenously with isotonic saline (control group; $n=15), 3 \mathrm{mg} / \mathrm{kg} / \mathrm{h}$ ketamine (ketamine group; $\mathrm{n}=17$ ), or 3 $\mathrm{mg} / \mathrm{kg} /$ nefopam (nefopam group; $\mathrm{n}=16$ ) respectively, followed by $3 \mathrm{mg} / \mathrm{kg} / \mathrm{h}$ morphine via IV-PCA for $24 \mathrm{~h}$ or until pain subsided in the PACU. The morphine dose was subsequently reduced to determine morphine consumption, during which the following vitals were carefully monitored: pulse oximetry (SPO2), respiratory rate $(R R)$, systolic and diastolic blood pressure (SBP and DBP), heart rate (HR), and temperature.

\section{Post-operative pain management and patient assessment}

The VRS was used to determine a patient's selfrated pain score verbally. Each patient selected a value on the scale that matched the degree of his or her pain at rest. The VRS ranged from 0-5, with the following scores: $0=$ no pain, $1=$ mild pain, 2 = moderate pain, $3=$ severe pain, $4=$ very severe pain (tolerable), and $5=$ excruciating (intolerable) pain. The VAS consisted of a horizontal line $100 \mathrm{~mm}$ in length, with the end points "no pain" and "worst imaginable pain" placed at each end. Patients were instructed to mark the line at the level that best described their experienced pain intensity [12]. Patients were queried about their level of satisfaction using a satisfaction score on a Likert scale that ranged from 0-3, with the following scores: $0=$ dissatisfied, 1 = least satisfied, 2 = partially satisfied, and $3=$ fully satisfied, at 2, 6, 12 and $24 \mathrm{~h}$ post-operatively. The morphine consumption rate and VRS and VAS scores were recorded at $0,0.5,1,2,6,12$ and $24 \mathrm{~h}$. Adverse effects such as sedation, sweating, pruritus, dizziness, dry mouth, events related to respiratory rate (RR), and post-operative nausea and vomiting (PONV) were recorded at $24 \mathrm{~h}$ post-operatively. All post-operative parameters were recorded by an anesthesiologist and a certified registered nurse anesthetist (CRNA) who were both unaware of the patient group allocation.

\section{Statistical analysis}

Baseline characteristics (demographic data) were compared across the various groups using Student's t-test. The incidence of side effects and the VRS and VAS scores were analyzed by the chi-square test and the Student's t-test, and the values were expressed as means \pm standard deviation (SD). One-way analysis of variance (ANOVA) was employed for comparisons among different groups. SPSS software version 17.0 was used for all analyses. A value of $p<0.05$ was considered statistically significant.

\section{RESULTS}

Table 1 presents the demographic and clinical information of the patients in the three analgesic groups, including surgery duration and patient gender, weight, ASA status, and age.

In total, 28 males (58 \%) and 20 females (42\%) participated in the present study. No significant differences were noted in any of the demographic data. Moreover, the average duration of the various abdominal surgeries was between 2.5 and $3 \mathrm{~h}$ in all three groups. A flowchart of the study design is shown in Figure 1.

The mean rate of total morphine consumption was markedly lower in both the ketamine ( $p<$ $0.01)$ and the nefopam $(p<0.05)$ groups compared with the control group (Fig 2). No significant differences in morphine consumption were noted between the nefopam and ketamine groups at $0,0.5,1$, and $2 \mathrm{~h}$ post-operatively; however, slight differences were observed at 6 , 12 , and $24 \mathrm{~h}$. The mean cumulative dose of morphine administered during the $24 \mathrm{~h}$ period was $33.4 \pm 2.5 \mathrm{mg}, 25.13 \pm 2.9 \mathrm{mg}$, and $26.94 \pm$ $3.5 \mathrm{mg}$ in the control, ketamine $(p<0.01)$, and nefopam $(p<0.05)$ groups, respectively. Patients in the ketamine group consumed less morphine than those receiving nefopam or saline.

Table 1: Demographic and clinical data

\begin{tabular}{lccc}
\hline Parameter & Saline $(\mathbf{n = 1 5})$ & Ketamine $(\mathbf{n = 1 7})$ & Nefopam $(\mathbf{n}=16)$ \\
\hline Gender $(\mathrm{M} / \mathrm{F})$ & $9 / 6$ & $8 / 9$ & $11 / 5$ \\
Age $(\mathrm{yr})$ & $48.94 \pm 9.42$ & $51.30 \pm 10.56$ & $50.40 \pm 11.47$ \\
Weight $(\mathrm{kg})$ & $68.34 \pm 10.31$ & $71.52 \pm 8.93$ & $72.44 \pm 11.25$ \\
Height $(\mathrm{cm})$ & $166.78 \pm 22.45$ & $168.32 \pm 28.98$ & $170.22 \pm 27.34$ \\
ASA status $(\mathrm{I} / \mathrm{II})$ & $11 / 4$ & $12 / 5$ & $12 / 4$ \\
Duration of surgery $(\mathrm{min})$ & $158.57 \pm 11.34$ & $177.43 \pm 30.95$ & $169.32 \pm 28.37$ \\
\hline
\end{tabular}

Values are the mean $\pm S D$. There were no statistically significant differences between the groups 


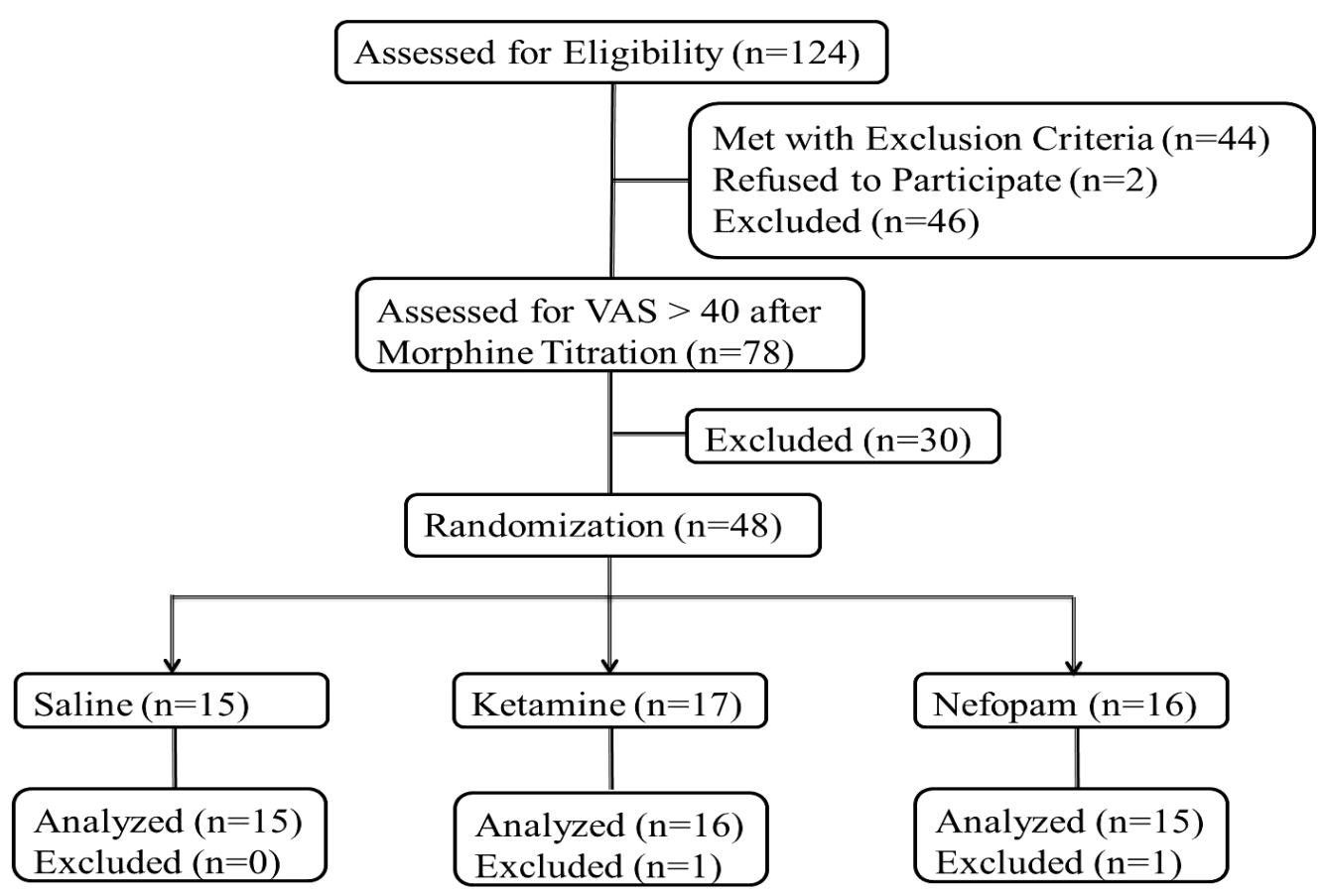

Figure 1: Flow chart of the present study design

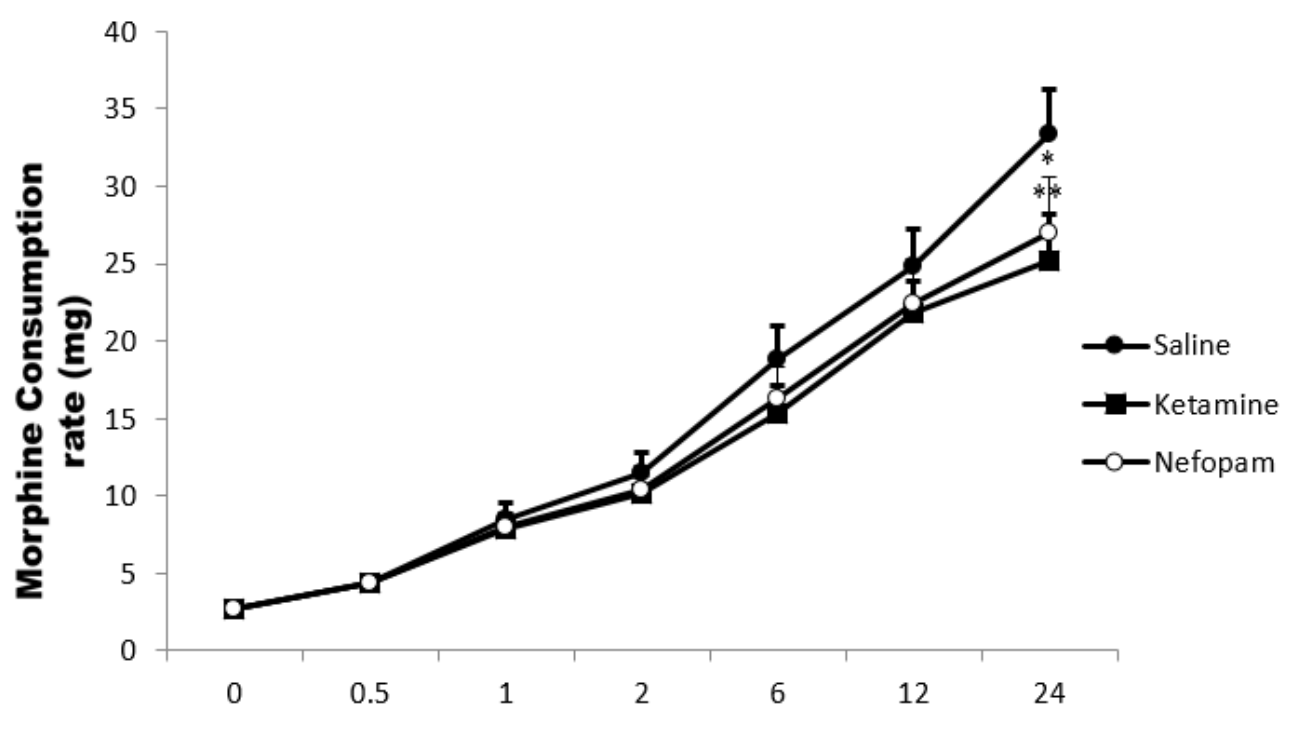

Time (min) of observation

Figure 2: Morphine consumption rate of abdominal surgery undergone patients receiving saline, ketamine, or nefopam. Values are expressed as the mean $\pm S D$; ${ }^{*} p<0.05,{ }^{* *} p<0.01$ compared with the saline group

The VRS and VAS scores were significantly higher in the control group than in the ketamine and nefopam groups at $1,2,6$, and $12 \mathrm{~h}$ postoperatively (Fig $3 \mathrm{~A}$ and $\mathrm{B}$ ). The pain scores of the control (morphine alone) and the nefopam and ketamine groups did not differ at 0 and $0.5 \mathrm{~h}$. The average VRS and VAS scores of the ketamine group $(p<0.01)$ were lower than that of the nefopam $(p<0.05)$ group at $1,2,6$, and $12 \mathrm{~h}$ post-operatively. However, none of the patients indicated a VRS score of 0 or 1.
Satisfaction scores were also higher in both the ketamine and nefopam groups compared with the saline group at $1,2,6,12$, and 24 h postoperatively. Moreover, ketamine administration resulted in a superior satisfaction score compared with the other groups. Patients given nefopam rated their satisfaction as moderate (Fig $4)$. 


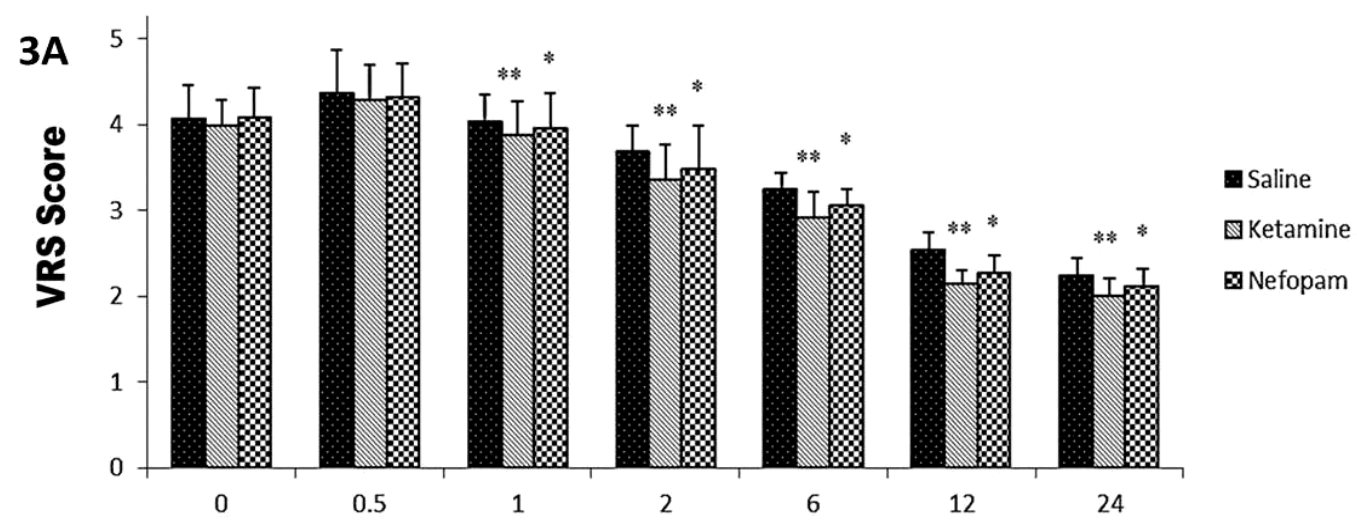

\section{B Time (min) of observation}

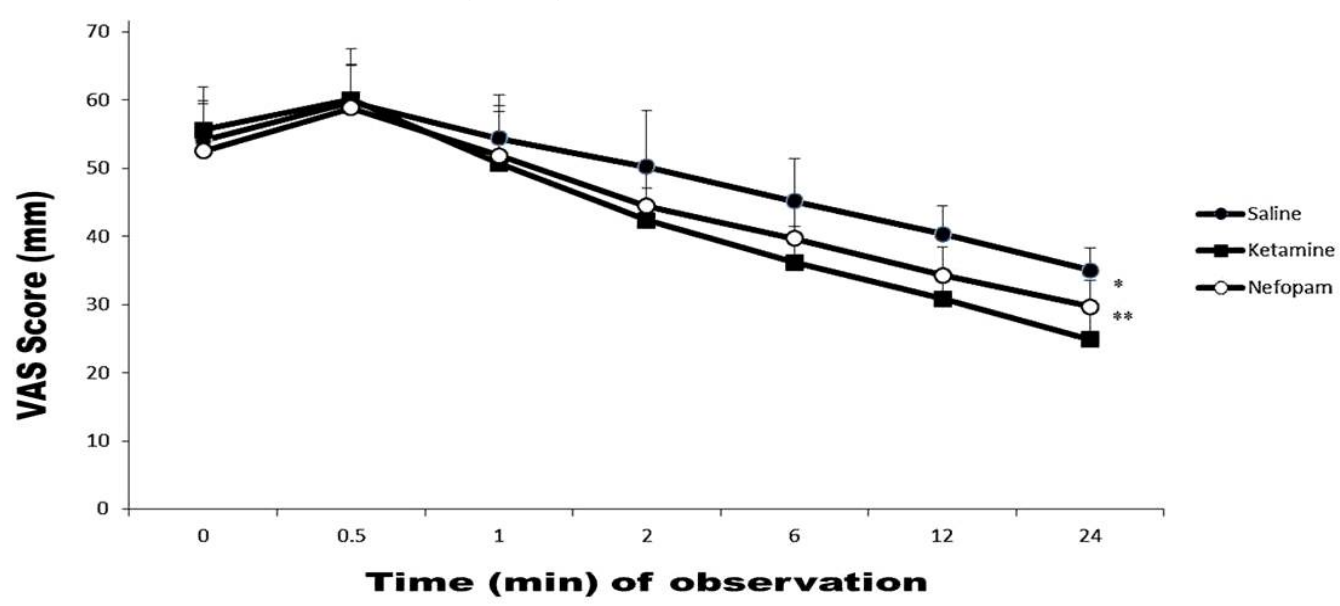

Figure 3: Post-abdominal surgery VRS (A) and VAS (B) scores of patients given saline, ketamine, or nefopam in combination with morphine. Values are expressed as the mean $\pm \mathrm{SD}$; ${ }^{*} p<0.05,{ }^{* *} p<0.01$ compared with the saline group

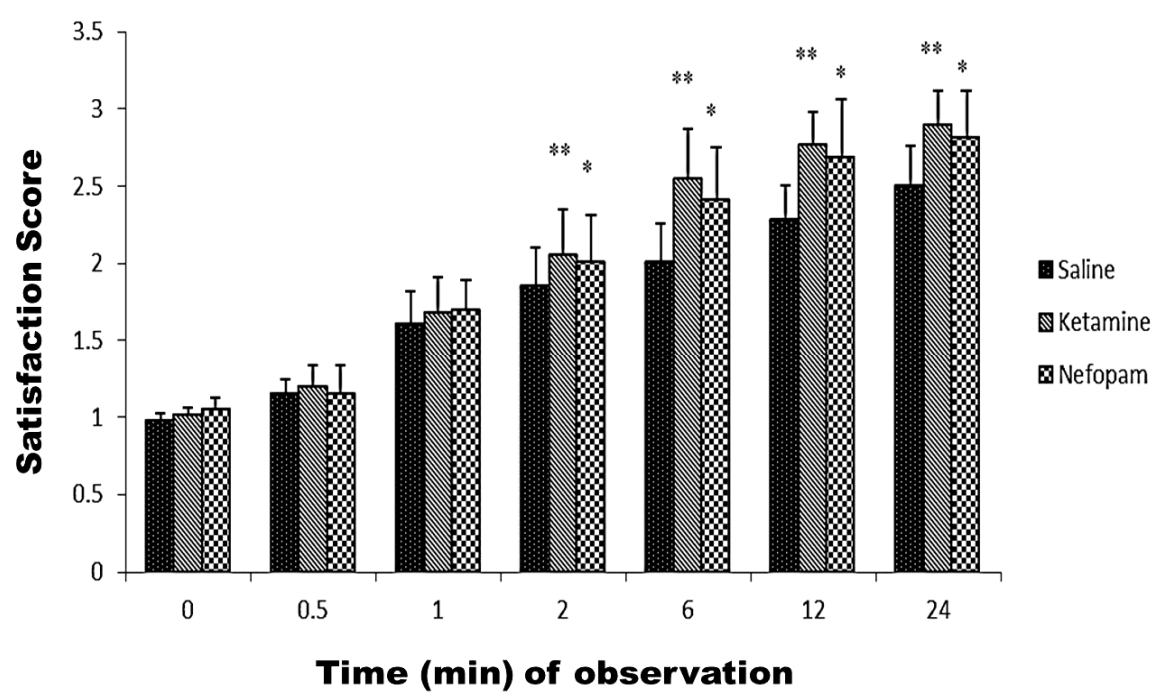

Figure 4: Satisfaction scores of abdominal surgery patients given saline, ketamine, or nefopam in combination with morphine post-operatively. Values are expressed as the mean \pm SD; ${ }^{*} p<0.05,{ }^{* *} p<0.01$ compared with the saline group

The incidence of various adverse effects is shown in Table 2. The overall occurrence of PONV was significantly higher in the control group than in the ketamine and nefopam groups.
Only four patients in the nefopam group and one patient in the ketamine group had PONV. The percentage of patients who experienced sweating, pruritus, mouth dryness, 
Table 2: Incidence of various adverse events, $24 \mathrm{~h}$ post-operative, in abdominal surgery patients given saline, ketamine, or nefopam in combination with morphine

\begin{tabular}{lccc}
\hline Variable & Saline $(\mathbf{n = 1 5})$ & Ketamine $(\mathbf{n = 1 7})$ & Nefopam $(\mathbf{n}=16)$ \\
\hline Sedation & $1(6.6)^{*}$ & $3(17.6)^{* *}$ & - \\
Sweating & $2(13.3)^{*}$ & - & $1(6.25)^{*}$ \\
Pruritus & $2(13.3)^{*}$ & - & - \\
Dizziness & - & - & - \\
Dry mouth & $3(20)^{\star *}$ & - & $2(12.5)^{*}$ \\
Respiratory rate & $4(26.6)^{*}$ & - & - \\
PONV & $6(40)^{* *}$ & $1(5.88)$ & $4(25)^{*}$ \\
\hline
\end{tabular}

Values are numbers of patients (\%); ${ }^{*} p<0.05,{ }^{* *} p<0.01$ compared to the other groups. PONV, post-operative nausea and vomiting

and RR was significantly higher $(p<0.05)$ in the control (saline) group. None of the patients experienced dizziness. Sedation was observed in three patients in the ketamine group, while dryness of the mouth was reported in two patients in the nefopam group. The overall frequency of adverse events in the control group was much higher than that in the ketamine and nefopam groups. Patients in the ketamine group experienced no adverse effects except for sedation and PONV, and thus had the lowest incidence of adverse effects.

\section{DISCUSSION}

This prospective study was designed to explore the efficacy of administering a combination of ketamine or nefopam with morphine (adjuvant therapy) to manage post-operative pain, as well as the associated incidence of adverse events, in abdominal surgery patients. Because morphine dose is limited by its toxicity, combining it with these drugs could provide better pain management, which would shorten hospital stays and enhance patient satisfaction. Major abdominal surgeries with upper abdominal incisions can result in severe abdominal pain if treated inadequately, and can cause shallow breathing and atelectasis, and thus, increase the incidence of post-operative morbidity and delayed recovery [13].

Low or sub-anesthetic doses of ketamine and nefopam, when combined with opioids, rarely induce adverse events or undesired hemodynamic alterations [14]. While morphine only delays the onset of NMDA receptor activation without direct inhibition, ketamine and nefopam are NMDA receptor antagonists. Therefore, it is logical to combine morphine with low doses of ketamine or nefopam to suppress hyperalgesia and the incidence of adverse effects produced by morphine. An opioid analgesic should be introduced and titrated to produce a maximum effect before a co-analgesic is added [15]. Hence, we used titrated morphine as an initial post-operative analgesic; if both drugs were introduced together, the risk of toxicity would increase and it would be difficult to determine the drug responsible for producing analgesia and/or any side effects. Thus, we followed this protocol to compare the effects of ketamine or nefopam combined with morphine. No demographic variables were significantly different between the treatment groups.

The total morphine consumption was defined as the amount of morphine administered by the PCA device throughout the first 24 post-operative hours, excluding the initial morphine titration. Patients in the saline group consumed more morphine than those given ketamine or nefopam. Ketamine, an NMDA antagonist, has undergone a recent revival of interest amongst acute care providers as an adjunct in post-operative pain management. Blocking NMDA receptors may enhance the efficacy of opioids and reduce the development of chronic pain syndromes [8]. In 2007, Galinski et al [16] concluded that ketamine reduced morphine consumption (administered by PCA) when compared with morphine alone, indicating that it has morphine-sparing activity.

Nefopam also indirectly modulates NMDA receptors, decreases c-Fos expression in the dorsal horn of the spinal cord in rats, and may also reduce allodynia and hyperalgesia when combined with an opioid [11]. Thus, both ketamine and nefopam prevent neuronal hyperexcitability and reduce morphine consumption. Several studies have shown that both ketamine and nefopam have morphinesparing effects when administered after abdominal surgery [10,13,17-22]. However, ketamine led to lower morphine consumption than nefopam in this study.

VRS and VAS are valid, reliable and appropriate tools for use in clinical practice to determine pain verbally and graphically, respectively, with patients attributing values that match the degree of pain experienced [23]. Saline group had higher VRS and VAS scores due to the lower analgesic 
effect of morphine alone. The combinations of morphine and ketamine or morphine and nefopam effectively relieved pain. These analgesic combinations act by attenuating neurotransmitter release through suppression of calcium entry, by enhancing outward movement of potassium ions, or by inhibiting adenylate cyclase. Ketamine can also prevent the opiateassociated activation of pro-nociceptive systems, which would increase opiate tolerance and thus decrease pain further [24]; in accordance, the ketamine group exhibited lower VRS and VAS scores than the nefopam and saline groups. Numerous preclinical and clinical reports have demonstrated that both ketamine and nefopam improve opioid analgesia $[5,6,13,22]$ due to synergistic mechanisms, thus decreasing pain intensity. Satisfaction scores were markedly higher in both the ketamine and nefopam groups, probably due to lower morphine consumption and lower VRS and VAS scores.

An adverse effect is an undesired harmful effect resulting from a medication or other intervention such as surgery. The most frequent adverse effects in patients given morphine alone were PONV, sweating, pruritus, dry mouth, and RR, which have previously been observed [25]. The most common side effects in the ketamine group were sedation and PONV, whereas sweating, dry mouth, and PONV were most common in the nefopam group. Kapfer et al [26] also showed that PONV, sedation, dry mouth, and sweating were the common adverse effects in nefopam and ketamine-treated individuals. Lower morphine consumption (morphine sparing activity) may be the reason for the lower incidence of adverse effects in both the ketamine and nefopam groups compared with the control group.

The present study demonstrates that the combination of morphine with low doses of ketamine or nefopam, delivered via IV-PCA, provides superior analgesic effects with fewer adverse events than morphine alone. Even though morphine combined with ketamine resulted in better outcomes, the exact mechanism of ketamine sparing activity is not fully understood. Further research is warranted to determine the precise molecular mechanism underlying the beneficial activity of this analgesic regimen.

\section{Limitations of the study}

This study is not without limitations. We evaluated acute pain for only a short duration (24 h) after different types of abdominal surgery. Moreover, since this was a pilot study, only a small number of patients participated, and the dose of analgesic used was low. For each analgesic, the mode and timing of administration, type of surgery, and the dosage used play crucial roles in post-operative pain management. Thus, finding a good analgesic regimen with an effective dosage and mode of administration for managing pain is necessary to enhance patient satisfaction.

\section{CONCLUSION}

The findings of the present study demonstrate that low-dose ketamine or nefopam infusion with morphine has significant opioid-sparing effects, and reduce pain intensity and incidence of various adverse events. Ketamine administration results in superior analgesic effects with a lower occurrence of adverse events compared with nefopam. Therefore, we recommend the use of ketamine combined with morphine for improved pain management, to shorten hospitalization, and to enhance patient satisfaction. Further research with different doses of these analgesics in large randomized clinical trials is required to validate these results.

\section{DECLARATIONS}

\section{Acknowledgement}

The authors thank Qilu Hospital of Shandong University for funding this project (no. QHSU235).

\section{Conflict of Interest}

No conflict of interest associated with this work.

\section{Contribution of Authors}

The authors declare that this work was done by the authors named in this article and all liabilities pertaining to claims relating to the content of this article will be borne by them.

\section{REFERENCES}

1. Eremenko AA, Kuslieva EV. Analgesic and opioid-sparing effects of intravenous paracetamol in the early period after aortocoronary bypass surgery. Anesteziol Reanimatol 2008; 5: 11-14.

2. Kollender Y, Bickels J, Stocki D, Maruoani N, Chazan S, Nirkin A, Meller I, Weinbroum AA. Sub-anaesthetic ketamine spares post-operative morphine and controls pain better than standard morphine does alone in orthopaedic-oncological patients. Eur J Cancer 2008; 44: 954-962. 
3. Paqueron $X$, Lumbroso $A$, Mergoni $P$, Aubrun $F$, Langeron $O$, Coriat $P$, Riou $B$. Is morphine induced sedation synonymous with analgesia during intravenous morphine titration? Br J Anaesth 2002; 89: 697-701.

4. Kim K, Kim WJ, Choi DK, Lee YK, Choi IC, Sim JY. The analgesic efficacy and safety of nefopam in patientcontrolled analgesia after cardiac surgery: $A$ randomized, double-blind, prospective study. J Int Med Res 2014; 42(3): 684-692.

5. Ren $Y Y$, Zhang $H Q$, Duan SH, Wang SD. Influence of Dexmedetomidine on Toxicity of Intrathecal Ketamine on Neonatal Rat Spinal Function. Trop J Pharm Res 2015; 14(3): 469-477.

6. Weinbroum AA. A single small dose of postoperative ketamine provides rapid and sustained improvement in morphine analgesia in the presence of morphineresistant pain. Anesth Analg 2003; 96: 789-795.

7. Menigaux $C$, Fletcher $D$, Dupont $X$, Guignard $B$, Guirimand $F$, Chauvin M. The benefits of intraoperative small-dose ketamine on postoperative pain after anterior cruciate ligament repair. Anesth Analg 2000; 90: 129135.

8. Laskowski K, Stirling A, McKay WP, Lim HJ. "A systematic review of intravenous ketamine for postoperative analgesia." Can J Anesthesia 2011; 58(10): 911-923.

9. Guirimand F, Dupont $X$, Bouhassira D, Brasseur L, Chauvin M. Nefopam strongly depresses the nociceptive flexion $(R(I I I))$ reflex in humans. Pain 1999; 80: 399-404.

10. Mimoz O, Incagnoli $P$, Josse $C$, Gillon MC, Kuhlman L, Mirand A, Soilleux H, Fletcher D. Analgesic efficacy and safety of nefopam vs. propacetamol following hepatic resection. Anaesthesia 2001; 56: 520-525.

11. Verleye M, Andre N, Heulard I, Gillardin JM. Nefopam blocks voltage-sensitive sodium channels and modulates glutaminergic transmission in rodents. Brain Res. 2004; 1013(2): 249-255.

12. Ferreira-Valente MA, Pais-Ribeiro JL, Jensen MP. Validity of four pain intensity rating scales. Pain 2011; 152(10): 2399-2404.

13. Tirault $M$, Derrode $N$, Clevenot $D$, Rolland $D$, Fletcher $D$, Debaene $B$. The effect of nefopam on morphine overconsumption induced by large-dose remifentanil during Propofol anesthesia for major abdominal surgery. Anesth Analg 2006; 102: 110-117.
14. Fortin D, Adams R, Gallez A. A blood-brain barrier disruption model eliminating the hemodynamic effect of ketamine. Can J Neurol Sci 2004; 31: 248-253.

15. McDonnell NJ, Keating ML, Muchatuta NA, Pavy TJ, Paech MJ. Analgesia after caesarean delivery. Anaesth Intensive Care 2009; 37: 539-551.

16. Galinski M, Dolveck F, Combes X, Limoges V, Smaïl N, Pommier $V$, et al. Management of severe acute pain in emergency settings: Ketamine reduce morphine consumption. Am J Emerg Med 2007; 25: 385-390.

17. Aveline C, Gautier JF, Vautier P, Cognet $F$, Hetet $H L$, Attali JY, Bonnet F. Postoperative analgesia and early rehabilitation after total knee replacement: $A$ comparison of continuous low-dose intravenous ketamine versus nefopam. Euro J Pain 2009; 13(6): 613-619.

18. Nesher N, Ekstein MP, Paz Y, Marouani N, Chazan S, Weinbroum AA. Morphine with adjuvant ketamine vs higher dose of morphine alone for immediate postthoracotomy analgesia. Chest 2009; 136: 245-252.

19. Bell RF, Dahl JB, Moore RA, Kalso E. Perioperative ketamine for acute postoperative pain. Acta Anaesthesiol Scand 2005; 49: 1405-1428.

20. Carstensen M, Moller AM. Adding ketamine to morphine for intravenous patient-controlled analgesia for acute postoperative pain: a qualitative review of randomized trials. Br J Anaesth 2010; 104: 401-406.

21. Tramoni G, Viale JP, Cazals C, Bhageerutty K. Morphine sparing effect of nefopam by continuous intravenous injection after abdominal surgery by laparotomy. Eur $J$ Anaesthesiol 2003; 20: 990-992.

22. Saghaei E, Moini Zanjani T, Sabetkasaei M, Naseri K. Enhancement of antinociception by co-administrations of nefopam, morphine, and nimesulide in a rat model of neuropathic pain. Korean J Pain 2012; 25: 7-15.

23. Williamson A, Hoggart B. Pain: a review of three commonly used pain rating scales. J Clin Nurs 2005; 14(7): 798-804.

24. Himmelseher S, Durieux ME. Ketamine for perioperative pain management. Anesthesiol 2005; 102: 211-220.

25. Sveticic G, Gentillini A, Eichenbruger U, Luginbuhl $M$, Curatolo M. Combinations of morphine with ketamine for patientcontrolled analgesia. Anesthesiol 2003; 98: 11951205.

26. Kapfer B, Alfonsi P, Guignard B, Sessler DI, Chauvin M. Nefopam and ketamine comparably enhance postoperative analgesia. Anesthes Analges 2005; 100(1): 169. 